Article

\title{
Understanding Social Media Logic
}

José van Dijck * and Thomas Poell

Department of Mediastudies, University of Amsterdam, The Netherlands

* Corresponding author

\section{How to Cite this Article}

van Dijck, J., \& Poell, T. (2013). Understanding Social Media Logic. Media and Communication, 1(1), 2-14.

\section{Acknowledgement}

This Article was published by Librello, Media and Communication's former publisher.

\section{About the Journal}

Media and Communication is an international open access journal dedicated to a wide variety of basic and applied research in communication and its related fields. It aims at providing a research forum on the social and cultural relevance of media and communication processes.

www.cogitatiopress.com/mediaandcommunication

\section{Editors-in-Chief}

Professor Bradley Greenberg, Departments of Communication and Telecommunication, Information Studies and Media, Michigan State University, USA

Professor Elisabeth Klaus, Department of Communication, University of Salzburg, Austria

\section{Managing Editor}

Mr. António Vieira, Media and Communication, Cogitatio Press, Portugal 


\title{
Understanding Social Media Logic
}

\author{
José van Dijck* and Thomas Poell
}

Department of Mediastudies, University of Amsterdam, Turfdraagsterpad 9, 1012 VT Amsterdam, The Netherlands; E-Mails: j.van.dijck@uva.nl (J.D.); t.poell@uva.nl (T.P.); Tel.: +31 20525298;

Fax: +31205254708

* Corresponding author

Submitted: 22 March 2013 | In revised form: 15 May 2013 | Accepted: 19 July 2013 |

Published: 12 August 2013

\begin{abstract}
Over the past decade, social media platforms have penetrated deeply into the mechanics of everyday life, affecting people's informal interactions, as well as institutional structures and professional routines. Far from being neutral platforms for everyone, social media have changed the conditions and rules of social interaction. In this article, we examine the intricate dynamic between social media platforms, mass media, users, and social institutions by calling attention to social media logic-the norms, strategies, mechanisms, and economies-underpinning its dynamics. This logic will be considered in light of what has been identified as mass media logic, which has helped spread the media's powerful discourse outside its institutional boundaries. Theorizing social media logic, we identify four grounding principles-programmability, popularity, connectivity, and datafication-and argue that these principles become increasingly entangled with mass media logic. The logic of social media, rooted in these grounding principles and strategies, is gradually invading all areas of public life. Besides print news and broadcasting, it also affects law and order, social activism, politics, and so forth. Therefore, its sustaining logic and widespread dissemination deserve to be scrutinized in detail in order to better understand its impact in various domains. Concentrating on the tactics and strategies at work in social media logic, we reassess the constellation of power relationships in which social practices unfold, raising questions such as: How does social media logic modify or enhance existing mass media logic? And how is this new media logic exported beyond the boundaries of (social or mass) media proper? The underlying principles, tactics, and strategies may be relatively simple to identify, but it is much harder to map the complex connections between platforms that distribute this logic: users that employ them, technologies that drive them, economic structures that scaffold them, and institutional bodies that incorporate them.
\end{abstract}

Keywords: Facebook; mass media; media activism; platform analysis; social media; Twitter; viral

(c) 2013 by the authors; licensee Librello, Switzerland. This open access article was published under a Creative Commons Attribution License (http://creativecommons.org/licenses/by/3.0/). 


\section{Introduction}

"Dutch teen's sweet sixteen party invitation goes viral on Facebook, ends in 3,000 rioting in Groningen suburb" was only one of many headlines summarizing the series of events that led to an outburst of violence in Haren (Netherlands) on Friday 21 September 2012 [1]. A girl posting an invitation to her sweet sixteen party accidentally put her Facebook-setting to "public", generating enormous buzz on social media platforms in the week preceding the party. When she realized her mistake, the teenager canceled the party, but this did not prevent thousands of people from organizing themselves online to join the celebration. Newspapers and television started to pick up the story a few days before the annulled gathering. The story got bigger as more people tapped into the viral stream. On the evening of 21 September 2012, broadcast media started to report live from Haren, where police had barricaded the streets while visitors from all over the country were pouring in. Some youngsters were wearing "Project $X$ Haren" T-shirts, after the recent American film about a party that grows out of control. The police could not prevent serious rioting and by the next morning, the peaceful suburb of Haren counted 34 injured and millions in damages.

After what became known as "the Facebook riots", people quickly started to point fingers at one or more visible culprits: Facebook, which sparked the riots or did nothing to prevent them from happening; mass media, which fanned the fire with their on site reporting, which some argued substantially aggravated the crowds' impact; the police who were ill prepared and did not redress social media signals seriously; and finally, the rioters who deployed social media to "inflame" innocent youth and encourage many to participate in an outburst of violence. In the Dutch press, some defended the neutrality of social media as channels of communication, while others disputed this. Most commentators agreed that although Facebook and social media in general could not be held responsible for the "spontaneous" revolt, users and institutions should become more aware of the impact of these new tools [2]. The Haren city council issued an investigation, resulting in a thorough analysis of the role (social) media played in these events [3]. The report concluded that neither mass media nor social media could be pinpointed as causing these riots, but their merging dynamics were instrumental in shaping the course of events.

Over the past decade, social media platforms have penetrated deeply into the mechanics of everyday life, affecting people's informal interactions, as well as institutional structures and professional routines. We could look at them as the latest innovation in computer-mediated communication that poses serious challenges to existing institutions, such as mass media and government authorities. Indeed, the fast growth of online platforms forces everyone to adapt to a new reality, where the mass distribution of information, news, and entertainment seems no longer the privilege of the institutional few. Fast-growing networks like Facebook and Twitter with millions of active users are rapidly penetrating public communication, affecting the operational and institutional power balance of media systems. But "social media" or "mass media" are hardly autonomous forces in the organization of social events. Phenomena like the Haren riots materialize through an intricate web of online and offline settings connected by a dynamic constellation of technological, economical, and socio-cultural mechanisms.

In order to understand how this new media ecosystem reshapes social orders or chains of events, we want to call attention to social media logic-the strategies, mechanisms, and economies underpinning these platforms' dynamics. This logic will be considered in light of what has previously been identified as mass media logic, which helped spread the media's powerful discourse outside its proper institutional boundaries. After reintroducing mass media logic, we will turn to social media logic and identify four grounding elements to describe how this logic functions: programmability, popularity, connectivity, and datafication. Social media logic, as we will argue, is increasingly becoming entangled with mass media logic; and even though these logics are mutually reinforcing, they are also succinctly different. The logic of social media, as was previously the case with mass media logic, is gradually dissipating into all areas of public life; the cultural and commercial dynamics determining social media blend with existing commercial and advertising practices, while also changing them. Far from being neutral platforms, social media are affecting the conditions and rules of social interaction. Therefore, their sustaining logic deserves to be scrutinized in detail to better understand its impact in various domains.

\section{Mass Media Logic}

During most of the twentieth century, mass media gained power not only by cementing their institutional status, but also by developing a commanding discourse that guided the organization of public space. The formal grid of understanding that steers information, news, and communication was effectively exported to vital areas beyond media organizations, where mass media gained legitimacy mostly through the influence of its logic. Over thirty years ago, David Altheide and Robert Snow (1979) defined (mass) media logic as a set of principles or common sense rationality cultivated in and by media institutions that penetrates every public domain and dominates its organizing structures: "In contemporary society, every institution has become part of media culture: changes have occurred in every major institution that are a result of media logic in presenting and interpreting activity in those institutions" ([4], p. 11). The power of mass media, they argued, was mostly diffused and exercised through discursive strategies and performative 
tactics that became accepted as "natural" or "neutral" in all kinds of institutional contexts.

So what strategies and tactics make up mass media logic in its original formulation? When defining media logic in the late 1970s, Altheide and Snow singled out a number of elements, partly relating to its ability to frame reality and partly pertaining to media's claim towards neutrality or independence. For instance, media logic presents the world as a continuous flow of events, an incessant stream of things and people "out there". The nature of media logic is "to saturate coverage of events over a short period of time, slack off, and eventually turn to something else" ([4], p. 238). Topics wax and wane in the public's attention, but there is nothing natural about this stream; media have a distinct interest in constantly renewing themes so people keep coming back to their outlets. This applied to print but even more so to television. According to Raymond Williams, broadcast media create a programmed flow, which captures the attention of audiences and glues them to the screen [5]. The rationality of quick turnover rates dominates the selection of news itself, like a commodity principle. Moreover, television's ability for liveness shows the tendency to stage its flow of programmed events as unmediated real-life registration [6-8]. Television cameras and broadcast techniques add immediacy and intensity to the rhetorical power of words: shots of bloody victims or sweating presidential candidates have emotional impact, enhancing television's potential to sway large audiences towards collective pathos.

Secondly, the tendency of mass media is to present themselves as neutral platforms that fairly represent different public voices and opinions, whereas in fact they operate as filters through which some people get more exposure than others. Implied in the original theory of media logic was the appearance of institutional independence-independence from state or commerce-and to present its products as balanced representations of the public interest by means of discursive and procedural strategies. Discursively speaking, news items were separated from advertisements, and opinion distinguished from facts. As Altheide and Snow observed, the seeming neutrality of media logic was activated through staging experts speaking on behalf of institutions (e.g. the police or science), or by singling out representatives of the people's voice. Some people become media personalities not as a result of their specific knowledge, but by virtue of their ability to fit in with specific media formats: "[T]heir opinion and advice is not sought for the knowledge they might have, but because of their fame as people who operate within the familiar form of media logic" ([4], p. 241).

Another part of media logic derives its impact from the way it has anchored its seeming independence and neutrality in standardized procedures, for instance, neutral presentation by anchors, coverage of events by reporters, and subjective commentaries by authoritative voices-formats that are widely adopted and imitated outside media proper. One of the most insidious aspects of media self-legitimation, Altheide and Snow ([4], p. 245) contended, was the use of ratings, polls, and other surveys as scientific evidence of audience demand and also as a legitimizing tool for amplifying "representative" public voices.

The articulation of media logic in the late 1970s posed an alternative view to the many institutional, techno-political, and economic theories of media-analyses that often regarded mass media as institutional occupants of the public sphere. Unfortunately, the theory of media logic was never updated to include the many significant changes media underwent in the last two decades of the twentieth century. One such important shift was the proliferation, in the early 1980s, of cable television and the emergence of special niche audiences rather than mass publics; another important change was the general commercialization of culture, where news and information were increasingly infused by advertising practices in which facts and opinion were progressively mixed [9-11]. Media logic adapted to these new market realities by deploying many of these proven strategies and tactics to reaffirm boundaries that had long started to erode: boundaries between news and advertisements, facts and opinion, public service and commerce.

As a result, so-called public values were transported outside its institutional sphere to enhance corporate or state legitimacy [12]. For example, the news routine of quoting certified experts was imitated in advertising, where professors in lab coats cited "evidence" of research outcomes to promote branded products. The division between content and commerce became even fuzzier as content producers-particularly producers of news-were pressured to obey to the laws of the market or give in to public demand [13]. Government officials began to hire public relations officers to massage their relationship with citizens; and politicians employed spin-doctors to influence public opinion and voters [14-16]. Commercial stations such as Fox News demonstrate how media outlets copy the superficial trappings of media neutrality while explicitly articulating an ideological stance. Over the past decades, broadcast producers perfected audiovisual grammar to steer collective emotions and feelings, and this part of media logic quickly disseminated to all kinds of areas. Political elections are no longer thinkable without the fight to control camera angles; the same spotlights framing movie stars and sports heroes also frame political messages. Coverage of citizen revolts (from Beijing's Tiananmen Square in 1989 to Cairo's Tahrir Square in 2010) would not have had worldwide impact without protestors understanding the laws of mass media logic, resulting in arresting images of bloody protestors, spokespersons, and gripping action footage [15,17-19]. Commercials, entertainment, and news all blend into a seamless flow of images, defined by the televisual laws of ever-shorter sound bites, glitzy shots, and poignant close-ups. 
These changes in media organizations as well as in mass media's technological affordances have rendered the explanatory power of media logic as a legitimizing force even more intriguing. However, while much critical work has focused on conceptualizing media as public spaces or spheres, media logic has remained under-theorized in communication and media studies. The allure of such focus becomes particularly poignant when new technological and economic mechanisms emerge, transforming the character of the media landscape at large and media logic in particular. Besides the general transformations of the 1980s sketched above, there are a number of developments that have reshaped media logic, including the emergence, in the 1990s, of computer mediated interaction through the Web, the ubiquity of mobile computing, and the growth of social media platforms. Various technological and cultural trends in computing converged in the meteoric rise of social media platforms, which, in turn, greatly accelerated the transformation of the media landscape as well as of other social domains. Along with these changes came a new set of technological, economic, and socio-cultural mechanisms, which we would like to refer to as social media logic. Social media logic needs to be distinguished from mass media logic because the two sets of strategies and tactics emerged from a different technological and economic lineage. We explore below how social media logic blends with "established" mass media logic, while also adding new elements and transforming already existing mechanisms.

\section{Elements of Social Media Logic}

Social media can be roughly referred to as a "group of Internet-based applications that build on the ideological and technological foundations of the Web 2.0 and that allow the creation and exchange of user-generated content" ([20], p. 60) The quick rise of social media platforms in the first decade of this century was part of a more general networked culture where information and communication got increasingly defined by the affordances of web technologies such as browsers and search engines. Social networking sites like Facebook, Twitter, and LinkedIn as well as usergenerated content sites, including YouTube and Flickr, became the core of a host of web-based applications that together formed an expansive ecosystem of connective media [21]. Inferring from these conditions, we contend that social media logic refers to the processes, principles, and practices through which these platforms process information, news, and communication, and more generally, how they channel social traffic. Like mass media, social media have the ability to transport their logic outside of the platforms that generate them, while their distinctive technological, discursive, economic, and organizational strategies tend to remain implicit or appear "natural". In order to explicate social media logic as a particular set of strategies and mechanisms, we select four main elements for further elaboration: programmability, popularity, connectivity, and datafication. The point of identifying these four elements is not to provide an exhaustive analytical model of social media logic, but to identify a few of its main contrivances and illustrate their systematic interdependence. In addition, we will argue how social media logic is entangled with mass media logic, and how this intricate choreography affects the relative shaping of private, corporate, and state forces.

\subsection{Programmability}

When print and broadcasting still dominated the mediascape, the term "programming" related to scheduled content. Following Raymond Williams, Altheide and Snow noticed how programming was an editorial strategy for channels and broadcasters to glue their audiences to the screen from one segment to the next $[4,5]$. In mass media logic, the term thus referred to technology and cultural form: the ability of a central agency to manipulate content in order to define the audience's watching experience as a continuous flow. When gravitating towards the Web, the concepts "programming" and "flow" acquired a different meaning, shifting their emphases from content and audiences to code and users, and from programmed flow to programmability. In social media logic, one-way traffic yielded to two-way traffic between users and programmers-a process that affected both the technological and social mediation of content [22]. On sites like Twitter or Reddit, users can post content and steer information streams, while the sites' owners may tweak their platforms' algorithms and interfaces to influence data traffic. Programmability can hence be defined as the ability of a social media platform to trigger and steer users' creative or communicative contributions, while users, through their interaction with these coded environments, may in turn influence the flow of communication and information activated by such a platform.

The first part of this definition is grounded in technology, and pertains largely to computer code, data, algorithms, protocols, interfaces and the platform organizations that are responsible for programming [23]. While algorithms are nothing but sets of coded instructions, it is important to observe how social media platforms shape all kinds of relational activities, such as liking, favoriting, recommending, sharing and so on. For instance, Facebook's interface channels users into "friending" other users, implicitly redefining this social concept [24]. Some algorithms, like the one underlying the "people you may know button" on LinkedIn, automatically suggest social relations on the basis of inferred data. The power of algorithms, as David Beer contends, lies in their programmability: programmers steer user experiences, content, and user relations via platforms [25]. 
These technological mechanisms are often invisible. Coding techniques are difficult to observe except through visible user interfaces and application programming interfaces (APIs), and sometimes though their (open) source codes. Unlike the television schedules of mass media logic, technological programmability in social media logic is hard to analyze in part because algorithms are proprietary and thus kept a secret, and partly because they are constantly adapted to evolving business models and user practices [24,26]. As American media studies scholar Tarleton Gillespie explains, the programmability of social interaction has become paradigmatic in a media environment dominated by platforms: we now rely on the algorithmic assessment of information just as we used to rely on credentialed experts or scientific evidence in the discourse of mass media [27]. Editorial (human) choices, as Gillespie contends, have not vanished; on the contrary, programmability means that human editorial selections are processed imperceptibly and automatically [28].

The second part of the programmability definition, though, relates to human agency: users retain significant agency in the process of steering programmability not only through their own contributions but also because they may resist coded instructions or defy protocols. In response to actual usage, a platform may need to adjust its policies in order to keep pleasing its crowds and advertisers. Reddit, a social media site with some 62 million users, illustrates this twotiered rationality: the site lets its registered users-anonymous or identifiable-post comments or links to topics deemed noteworthy. Reddit generally leaves more power to its users in terms of what to post and how to channel attention to a topic than Facebook or YouTube. Anyone who starts a "SubReddit" becomes his or her own editor of the flow of information, deciding who can add and who has access. As an "attention aggregator", Reddit relies on its algorithms as well as on the vigilance of its users to operate the platform; its operators refuse to take on the role or responsibilities of news reporters, thus defying an editorial function. However, exporting this new social media logic-the mutual shaping of the information flow by owners and users - to discourses outside the platform proper, inevitably leads to a blend with mass media logic. In April 2013, a police hunt for the suspects of the Boston Marathon bombers fueled a SubReddit "findbostonbombers", which led to a stream of amateur sleuths and false accusations towards innocent high school students. When Reddit was vehemently criticized for its lack of editorial accountability, the platform issued an apology and promised to change its tactics-enhancing its codes and protocols as well as fortifying its users vigilance and filter substreams for their tone of voice.

The logic of programmability thus inevitably mixes the crowdsourcing principles of social media with the editorial values expected of mass media. In mass media logic, "programming" referred to an editorial strategy that manifested itself through the selection, juxtaposition, and promotion of certain items in the flow of scheduled content. Now that the flow has taken an "algorithmic turn," content is not just programmed by a central agency, even if this agency still has considerable control; users also participate in steering content, distinguishing it from William's programmed flow [29]. The Reddit example shows how platform owners are not the only power brokers in the social media universe: users themselves also have the ability to shape these algorithmic mechanisms. They can either "go with the flow" or they can manipulate coded interaction, for instance by massively retweeting or liking particular content, thereby pushing a topic to become trending. In doing so, platform programmers and users continuously negotiate the terms of social interaction. In the case of the Facebook riots in Haren, cited at the beginning of this article, users exploited the programmability of various platforms, not only by deliberately ignoring the erroneous privacy setting of the sixteen-year-old girl, but also by exploiting the platform's functionality to send the message to as many "friends" as possible.

Due to the two-way nature of online traffic, programmability has serious consequences not only for the design of "platformed" sociality but also for social activities mitigated by social institutions, such as the mass media and law and order. Although programmability might be considered as a unique game changer, as a central element of social media logic it is inescapably part of a larger configuration. It has not only become intricately intertwined with the logic of mass media, but also with the strategies of advertising, public relations, activism, and other public discourses. We will return to this larger configuration in a later section.

\subsection{Popularity}

A second principle of social media logic is popularity. Mass media logic already divulged a potent mechanism for pushing "likeable" people to become media personalities; depending on their ability to play the media and lure crowds, a variety of actors, from politicians to entertainers, accumulated mass attention, often achieving the status of celebrity. Besides fame and popularity, mass media's power in terms of agenda setting or pushing certain topics to the fore has been a much-theorized subject amongst academics [30]. As Altheide and Snow already contended in 1979, mass media's ability to shape public opinion by filtering out influential voices and assigning some expressions more weight, attested to its power [4]. In the early years of their existence, social media platforms held the promise of being more egalitarian and democratic than mass media in a sense that all users could equally participate and contribute content. However, as platforms like Facebook and Twitter matured, their techniques for filtering out popular items and influential people became gradually more sophisticated. Al- 
though each platform's strategies for advancing some topics and prioritizing particular users differ, we will try to describe the general underpinning dynamics involved in online popularization. How does the pursuit of online attention become part of a media logic that influences what people find important? And how does this logic mesh with (mass) media logic in online or offline public discourses, even if they arise from separate conditions?

In line with the feature of programmability, popularity is conditioned by both algorithmic and socioeconomic components. Each platform has its distinct mechanisms for boosting popularity of people, things, or ideas, which is measured mostly in quantified terms. Inscribed in Facebook's EdgeRank and Twitter's Trending Topics are algorithms that push some topics and devalue others $[24,28,31]$ Facebook's Like-scores automatically select emotive and positive evaluations of topics, rather than asking for complex assessments. The Like-mechanism claims to promote a social experience but the button simultaneously figures in an automated "like-economy" [32]. Along similar lines, Twitter's Trending Topics feature enables users to boost certain topics or news items, while Retweets offer a tool to widely "endorse" a specific tweet. But Twitter also actively pushes Promoted Tweets-paid for by companies and personalized via algorithms to fit specific Twitter-streams. In spite of the platform's egalitarian image, some people on Twitter are more influential than others, partly because the platform tends to be dominated by few users with large followings, partly because the platform assigns more weight to highly visible users. For instance, users such as CNN's Middle East correspondent Christiane Amanpour get more weight than other experts or witnesses. Popularity boosting is thus two-way traffic: algorithms automatically assign differentiated value, but users themselves may also engage in concerted efforts to lift certain people's visibility.

Platforms themselves have an increasing interest in standardizing their metrics and making them meaningful in social life outside their platform proper. The logic of online popularity resides in banners for "most viewed" videos on YouTube, friend stats on Facebook, or follower counts on Twitter. Furthermore, each platform is in the business of developing its own thermometer for measuring aggregated popularity or influence: we now have Facebook Memology for a top-ten of most popular topics, Google Analytics for measuring a site's traffic and sales, and Twitter's top-100 of people with the largest followings. Each corporation actively seeks to promote their popularity and ranking mechanisms in order to enhance the value of its platform and its users.

Besides individual platforms deploying these strategies, there are also a number of new platforms who measure popularity scores and reputational rankings across the board: Klout scores calculate individual user's presence and influence on all platforms by deploying complex-and often controversial-algorithms [33].
Based on this number, advertisers or employers may single out certain "superusers" and pay them to perform promotional tasks or jobs ("People with a Klout score below 45 need not apply"). In the online ecology of platforms, popularity and influence have created their own standards, complementing the popularity metrics already distributed by mass media.

On the one hand, social media logic complements mass media logic and enhances its dominant norms and tactics, just adding an extra dimension. Traditional mass media have wielded popularity filters for decades; one just needs to think of Time Magazine's list of "100 most influential people" and its "Person of the Year". And, as Altheide and Snow already noticed, the "voxpop strategy" is an age-old tactic-singling out citizens as spokespersons for a certain public segment [4]. Social media's claim that online metrics complement popularity tactics already wielded by mass media is therefore an evidential part of its logic. Influential Twitter users are beginning to find their way into the star-system of mass media alongside media celebrities; TV-shows increasingly define the "news of the day" or decide whom to interview on the basis of Twitter trends or by looking into Facebook discussions. Journalists from news media often treat tweets from celebrities or politicians as quotes-a peculiar reinforcement of Twitter's powerful function as a public relations tool. Platform metrics are increasingly accepted as legitimate standards to measure and rank people and ideas; these rankings are then amplified through mass media and in turn reinforced by users through social buttons such as following and liking.

What makes this element of social media logic different from mass media logic, though, is its ability to measure popularity at the same time and by the same means as it tries to influence or manipulate these rankings. The entangled activities of measuring and manipulating expose a platform's technological affordances, while concurrently reflecting users' ability to push specific interest to the frontlines of public attention. Groups of users who decide something needs to become "trending" can orchestrate a publicity wave to promote a particular item, which, as the Occupy movement protestors found out, can be challenging on popular platforms such as Twitter [34] In the example of the Facebook riots in Haren, a group of opportunists shrewdly deployed the Like and ReTweet buttons to stage a party that was not a party, and they managed to mesh up their powerful social tools with the prevailing tactics of mass media to achieve their preset disruptive goals. Along similar lines, Facebook and Twitter's platform owners have used their popularity rankings to promote commercial, public, or charity causes (e.g. organ donation by Facebook's Mark Zuckerberg) [35]. It is exactly the export of social media popularity mechanisms to other social or commercial environments that proves the efficacy of its logic in challenging existing social hierarchies or unsettling discursive orders. 
Mass media logic and social media logic get incrementally entangled in defining the popularity of issues and the influence of people. Popularity becomes enmeshed in a feedback loop between mass and social media, and, as was argued in the case of programmability, becomes part of a larger cultural arena where different institutional discourses and counter-discourses engage in a struggle to make their logics more pressing. Two more elements play a central role in the syntax of social media logic: connectivity and datafication.

\subsection{Connectivity}

In Altheide and Snow's theory on mass media logic, "the media" was generally presented as an amorphous palette of media organizations whose aim-dependent on their public or commercial objectives-is to connect content to citizens or to link advertisers to consumers [4]. Traditional media institutions have always addressed particular national or regional audiences in crafting news, information, and entertainment while selling audience attention to geographically or demographically assorted customers. When social media platforms emerged in the early 2000s, their primary pursuit seemed to be connectedness: Facebook, established in 2004, wanted college students to be able to connect and share, whereas user-generated content platforms such as YouTube, started in 2005, aimed at connecting users to (self-made) content. Many social media platforms-the most prominent of these being Facebook, YouTube, and Twitter-still promote their networked services as enablers of human connections. However, even if human connectedness or "participation" is still a valid part of social media's logic, a more encompassing and accurate term to capture this element of logic is connectivity. Connectivity, which originated as a hardware term, refers to the socio-technical affordance of networked platforms to connect content to user activities and advertisers. More precisely, in a connective ecosystem of social media, the "platform apparatus" always mediates users' activities and defines how connections are taking shape, even if users themselves can exert considerable influence over the contribution of content.

Connectivity partly overlaps but also distinctly differs from the notion of "spreadibility" introduced by Henry Jenkins, Sam Ford and Joshua Green [36]. While spreadibility recognizes "the importance of the social connections among individuals" they contend that these connections are merely "amplified" by social media platforms ([36], p. 6). The notion of spreadibility accentuates the power of audience agency, while deemphasizing the power of platform agency as a steering force. Connectivity, instead, equally emphasizes the mutual shaping of users, platforms, advertisers, and, more generally, online performative environments. Unlike mass media, social media platforms seldom deal with "natural" geographically or demographically delineated audiences; instead, they exped- ite connections between individuals, partly allowing the formation of strategic alliances or communities through users' initiative, partly forging target audiences through tactics of automated group formation ("groups you may be interested in" on Flickr) or personalized recommendations ("People who bought this item also bought..." on Amazon). Connectivity introduces a bipolar element into the logic of social media: a strategic tactic that effectively enables human connectedness while pushing automated connectivity. A number of theorists have chosen one side of this double logic, either to hail social media's liberating and communitarian potential, or to lament some platforms' predispositions as vehicles for customized advertising [37]. Our point in introducing the element of connectivity is to argue how social media logic does both at the same time. Let us look more closely to each end of this fallacious opposition.

The human connectedness efficacy of social media derives from early network sociology. Well before the rise of social platforms, sociologist Barry Wellman and colleagues argued that new media technologies involve a substantial shift in sociality from densely knit groups to loosely bounded social networks of relations, which he labels "networked individualism". Networked individualism presupposes that people directly connect to other people with whom they are involved in specialized relationships of common interest. This type of sociality revolves around the person rather than the group or locality $[38,39]$. New media, and especially also social platforms, ostensibly offer users the opportunity to pick and choose others to connect with and communicate on a personal basis. From this perspective, these media allow individuals to create their own customized social networks and communities (for a critical analysis of these trends see $[40,41]$ ).

Particularly interesting in this regard is the work by Bennett and Segerberg, who observe in their research on contemporary protests a shift from "collective" action to "connective" action [42]. They maintain that protest movements have traditionally depended on the construction and spreading of collective identification and action frames, which require formal hierarchical organizations and membership groups, to educate people and tie them to these frames [43-45]. According to Bennett and Segerberg, in contemporary protests this type of collective action is mixed with connective action-a hybrid that increasingly applies "to life in late modern societies in which formal organizations are losing their grip on individuals, and group ties are being replaced by large-scale, fluid social networks" ([42], p. 748). The authors emphasize that these networks do not require strong organizational control or a collective identity; instead, social technologies function as organizing agents. For instance, in the 2011 Occupy movements, technology-enabled personal networks did not simply function as communication systems but also empowered flexible organizations that allowed rapid action and coordinated adjustments. In our example of the Haren riots, people 
who had never met before rapidly refashioned Facebook and Twitter into organizational instruments.

In the double logic of connectivity, the flipside of networked individualism seems to be networked customization or automated personalization. When mass media still reigned, the alliance between consumers, content (or products) and advertisers always entailed a strategic deployment of recommendations and social networks to sell goods or services. Whether it be doctors in white coats, department store "loyalty-cards", neighbors organizing Tupperware parties, or endorsements from friends or celebrities-recommendation culture predates the advent of social networks. What is new in the context of social media networks, though, are the mechanisms of deep personalization and networked customization. These terms refer to online content calibration based on assumptions about individual user's needs and platform owners' or advertisers' interests. Connectivity should thus be seen as an advanced strategy of algorithmically connecting users to content, users to users, platforms to users, users to advertisers, and platforms to platforms. But the boundaries between human connections and commercially and technologically steered activities are increasingly obfuscated. For instance, automated links between users and products via Facebook Likes help advertisers utilize recommendation tactics for promoting products to "friends"-even if users are unaware of their being used for these purposes.

The recommendation culture grounded in automated connectivity shows the same Janus-face quality as we noticed with regards to networked individualism: some users appreciate the service offered by platforms to connect them to likeminded people, preferred items, or individualized taste; others loathe networked customization as a signal of intruded privacy or commercial exploitation of user information. Our point is not to side with any one side of this contentious equation, but to analyze how the connectivity element, as part of social media logic, is deployed to reshape hierarchies between private, public, and corporate interests. Connectivity in the context of both networked individualism and networked customization are significant new armaments in the struggle to redefine the boundaries between private and public and between commerce and state. Even though YouTube, Facebook and Twitter employ different mechanisms for enabling and forging connections, their various strategies fit a coherent logic. However, if we want to understand the mechanisms underpinning their interoperability, we need to turn to the fourth element in which social media logic is rooted: datafication.

\subsection{Datafication}

Part of mass media logic, especially television, was always the ability to reach mass audiences in real time coupled onto their ability to do audience research. Television's magic was (and still is) its ability to draw large crowds to watch live images-liveness still carrying the connotation of unmediated events evolving in real time, simply "captured" by the camera's eye and often signifying emotion and intensity $[6,8]$. Knowing more about viewer's profiles and tastes not only helped fine-tune programming decisions but also provide advertisers with precise figures to make paid messages more effective. Altheide and Snow already remarked how the use of ratings, polls, and other surveys served as predictors of audiences' predilections [4]. One might argue that mass media's ability to enhance audience predictability and to provide real-time audience experiences is an essential ingredient of its powerful logic. If we subsequently look at social media logic, we may discern how platforms have developed their own strategies for predicting and repurposing user needs, while also nursing their own equivalent of "real-timeness". Both notions, we contend, are grounded in the principle of datafication.

Datafication, according to Viktor Mayer-Schoenberger and Kenneth Cukier, refers to the ability of networked platforms to render into data many aspects of the world that have never been quantified before: not just demographic or profiling data yielded by customers in (online) surveys, but automatically derived metadata from smart phones such as time stamps and GPS-inferred locations [46]. When it comes to computer-mediated communication, each type of content-be it music, books, or videos-is treated as data; more specifically with regards to social networking platforms, even relationships (friends, likes, trends) are datafied via Facebook or Twitter. All three elements heretofore explored-programmability, popularity, connectivity-are grounded in the condition of datafication. In early theories of social media, (meta) data were often considered a byproduct of online networks, but as platforms gradually matured, they have turned more into data firms, deriving their business models from their ability to harvest and repurpose data rather than from monetizing user activity proper [40]. Datafication endowed social media platforms with the potential to develop techniques for predictive and real-time analytics.

Social media platforms, like mass media, handle a variety of online systems for rating, polling, and surveying user responses; but beyond expressly triggered responses, platforms ostensibly have the capacity for polling built into their architecture. Facebook and Twitter increasingly wield their potential to mine online social traffic for indicators of trending topics, keywords, sentiments, public viewpoints, or frequently shared and liked items. Microblogging tool Twitter, more than any other platform, promotes itself as an echo chamber of people's opinions, even positioning itself as a replacement of offline opinion polls [47]. The idea that social media are neutral, unmediated spaces is an important assumption ingrained in many definitions of data flows. Part of social media's logic lies in the assertion that data are "raw" resources merely being "channeled" through online veins, allow- 
ing researchers to perform "opinion mining" or "sentiment analysis" [48-50]. Twitter supposedly measures informal sentiments, feelings, or underbellies of "the people" at a stage when they are still in the process of becoming "official" public opinion.

Lisa Gitelman aptly coined the adage "'raw data' is an oxymoron", meaning that data are always already prefigured through a platform's gathering mechanisms [51]. Moreover, in processing data, a platform does not merely "measure" certain expressions or opinions, but also helps mold them. In opening up "spontaneous" sentiments and opinions to the public eye, platforms have rendered them formalized and preformatted expressions-even though many tweets appear, to say the least, unpolished. Hence, they can be assessed and influenced by third parties. Opinions and sentiments expressed via Twitter are extremely vulnerable to manipulation-following a similar dynamic as social theorists previously identified as pertaining to the role of opinion polls in mass media logic [52]. The idea that you can tap into people's unconsciousness or "idea formation" without affecting the processes of opinion making is a basic misconception, which goes back to the classic observer effect-a concept familiar to research method literature across disciplines [53].

What makes datafication a crucial characteristic for social media logic is its ability to add a real-time data dimension to mass media's notion of liveness. Facebook, LinkedIn, and particularly Twitter process large quantities of users' behavioral data every second. Much of social media data's value lies in their realtime "live" appearance: platforms claim they can track instantaneous movements of individual user behavior, aggregate these data, analyze them, and subsequently translate the results into valuable information about individuals, groups, or society at large. Social media logic of detecting representative trends based on real-time analytics is increasingly mingling with polling strategies established by mass media logic. For instance in the case of television audiences, Twitter claims to have equaled the Nielsen ratings technique to measure evaluative viewer responses [54]. Social media data streams are increasingly used as real-time analytics to complement or replace traditional polls issued by news media or professional agencies. While the real-timeness of social media significantly differs from the liveness of television, the blend of these two has considerable implications for both types of media as well as for public discourse at large. Think, for instance, of online analysts tracking Twitter data during live broadcasts of political debates, while partisan lobbyists are simultaneously trying to influence the course of the debate via Twitter $[55,56]$.

While datafication underpins the online platforms' strategies of predictive and real-time analytics, it does not intrinsically ascribe either commercial or public meaning to social media logic; instead, the deployment of these tactics in specific (institutional) contexts affords users and platform operators to attribute meaning. The principle of datafication can be used to predict user taste and insert personalized ads-as discussed in the previous section. However, data streams can also be aggregated to identify public health issues, such as flu-epidemics being traced through Twitter data. Consequently, this information can be used to send targeted ads for flu medication to all Twitter users in a particular afflicted area or to those twitterers using specific key words. The very same data can serve as input for epidemiologists to help develop early warning systems.

Many (state and corporate) sectors are currently experiencing the power of datafication strategies developed by social media, and try to incorporate them into their arsenal of available instruments. Police or law enforcement, for instance, can use real-time data for surveillance purposes. In the case of the Haren riots, police inspectors used the many videos of rebelling youngsters-put up on YouTube by youth themselves on the evening of the riots to attract more people to the scene-for the purpose of identifying and bringing to court a number of law offenders. Platforms like Twitter generate piles of data that may be extremely relevant to researchers interested in understanding social movements, group behavior, or largescale health trends. Authorities or corporations, for their part, may assign very different value or meaning to interpretations pursed out of these data piles.

One thing we should always take into account is the fact that generators of online data, particularly social media platforms like Twitter, Facebook, YouTube, and LinkedIn, are never neutral channels for data transmission. An important aspect of datafication is the invisibility or naturalness of its mechanics: methods for aggregation and personalization are often proprietary and thus often inaccessible to public or private scrutiny. Questions of ownership and privacy concerns are commonly leveled at data themselves: who can access private data and who is allowed to sell aggregate data? Can platforms be forced to surrender users' private data to the authorities? The effectiveness of legislation that regulates agency and ownership in democracies that function mostly through national legislative contexts is increasingly problematic in a world where social media companies and data firms operate globally.

As important as these questions are, datafication logic also triggers more profound questions concerning the changing norms of a data-driven, global social economy. Reflecting on the underlying principle of datafication, it again becomes clear how the rise of social media affects user agency in complex ways. As Wendy Chun has noticed, interactive real-time interfaces empower users and "buttress notions of personal action, freedom, and responsibility," while at the same time they empower platforms to steer and exploit users' activities ([57], p. 74). The invisibility of datafication processes prompts questions about the actual relationship between data and users: are (real-time) data 
flows indeed a reflection of real live activities, or are they the result of manipulative monitoring and steering? In the words of Louise Amoore ([58], p. 24), realtime data flows may say less about us, but more about "what can be inferred about who we might be".

Combined with the elements of programmability, popularity, and connectivity, the principle of datafication has profound implications for the shaping of social traffic. Predictive analytics and real-time analytics are new tools in the struggle to prioritize certain (corporate, public, or private) values over others. We should try to understand these complex dynamics not just as they unfold within the boundaries of social media platforms proper, but in their confrontations with different logics dominating other institutional contexts. Therefore, it is crucial to further develop a theoretical model that helps understand how all elements work interdependently in creating a coherent fabric, and also helps explain how this social media logic mixes with (offline) institutional logics. The double-edged sword of empowerment-of users and platforms - is a recurring trope in the evolving socio-technical logic of social media.

\section{Social Media Logic and the Redefinition of Public Value}

The four elements of social media logic-programmability, popularity, connectivity and datafication-are pivotal in understanding how in a networked society social interaction is mediated by an intricate dynamic of mass media, social media platforms, and offline institutional processes. Over the past years, social media logic has gradually infiltrated mass media logic, sometimes enhancing it, sometimes undercutting or replacing parts of it. By shifting our focus away from institutions to (social) media logic as a transforming force, we wanted to identify key principles propelling social interaction in a networked data-driven ecology. Concentrating on the mechanisms and strategies at work in social media logic, we tried to theorize a new constellation of power relationships in which social practices are profoundly reshaped [17]. We raised questions such as: How does social media logic modify or enhance existing mass media logic? And how is this new media logic exported beyond the boundaries of (social or mass) media proper?

The principles, mechanisms, and strategies underlying social media logic may be relatively simple to identify, but it is much harder to map the complex connections between platforms that distribute this logic: users that use them, technologies that drive them, economic structures that scaffold them, and institutional bodies that incorporate them. If we return to the example of the "Facebook riots" in Haren, cited at the beginning of this article, we refused to pinpoint one particular actor as the main culprit of an unpredicted series of events. What we did instead was to "reassemble the social", to use Bruno Latour's terminology, by deconstructing the logic by which these events occurred; not to locate a responsible actor or cause, but to learn more about the mechanisms and principles involved in the shaping of such events. [59]. Put simply: what happens when social media logic meets other institutional logics outside the context of social media platforms proper? In contemporary society, no institution can afford to look away from this logic because they have all become implicated in the same media culture: every major institution is part and parcel of this transformation in which the social gets infiltrated by a revamped media logic.

Over the past few years, social media have sometimes erroneously been regarded as ready-to-use tools for citizens, rioters, journalists, and activists to bring about social change, whether civil disruption, such as in Haren, or social uprisings, such as the ones in Tunisia and Egypt in 2011, which were casually tagged as "the Twitter revolutions". Epithets such as these divulge deceptive assumptions about the role of social media and their relation to mass media, users, and social institutions $[60,61]$. In the field of social activism, Facebook, YouTube, and Twitter are attributed momentous influence in the processes of mobilizing a following. As we have argued in this article, social media platforms can neither take credit nor blame for single-handedly transforming social processes or for turning around events. Like the mass media in the 1960s and 1970s, which were regarded as major influential forces in reshaping social order, social media, in the first decades of the new millennium, are likely to be seen as new unruly forces in a global transformation.

We neither intend to applaud the successes of these media nor rally against their insidious affects; the aim is to systematically analyze social media mechanisms as sources of transformation. Examining media logic, mass media and social platforms can hardly be seen as separate forces when it comes to controlling information and communication processes. As conventional mass media are just starting to grapple with this new logic, other institutions, too, realize they can hardly escape the imperative of social media logic. Not just police, law enforcers, and activists, but all kinds of actors-in education, politics, arts, entertainment, and so forth-are confronted with the basic contrivances of programmability, popularity, connectivity, and datafication. The elements of social media logic identified in this chapter should help to understand the nature of communication and information processes in the networked conditions of social life. By offering a systematic exploration of the logic sustaining this messy dynamic, we hope to inspire other researchers to look at specific case studies through this analytical prism and to critically interrogate the connections we have drawn. 


\section{References and Notes}

1. One example of international press coverage was a report in the Daily News/New York Daily. 22 September 2012. Available from: www.nydailynews.co $\mathrm{m} /$ news/world/dutch-teen-sweet-16-party-invitation-vi ral-facebook-ends-3-000-rioting-groningen-suburb-art icle-1.1165386 (accessed on 29 July 2013).

2. As one editorial in a prominent Dutch national newspaper stated: "Social media are not the cause of these riots; in the past, a call to arms on radio could mobilize a bunch of people. However, broadcasting was then still in the hands of professionals. With the advent of social media, everyone is a broadcaster. Photos or videos posted directly on social media can reach millions of people. We cannot stop or censor social media; users and society will have to learn how to deal with them". (editorial Trouw, 22 September 2012; translation by authors).

3. A committee chaired by former Amsterdam mayor Job Cohen and including communication and media experts published their report De weg naar Haren in March 2013. See: Commissie 'Project X' Haren. De weg naar Haren. De rol van jongeren, sociale media, massamedia en autoriteiten bij de mobilisatie voor Project X Haren [The way to Haren. The role of teenagers, social media, mass media and authorities during the mobilization for Project X in Haren]. Groningen, The Netherlands: Commissie 'Project X' Haren; 15 March 2013. Available from: http://www.burgemeeste rs.nl/facebookrellenv (accessed on 29 July 2013).

4. Altheide DL, Snow RP. Media Logic. Beverly Hills, CA, USA: Sage; 1979.

5. Williams R. Television: Technology and Cultural Form. London, UK: Fontana; 1974.

6. Auslander P. Liveness: Performance in a Mediatized Culture. London, UK: Routledge; 1999.

7. Bolter JD, Grusin R. Remediation. Understanding New Media. Cambridge, MA, USA: MIT Press; 1999.

8. Couldry N. Liveness, "Reality", and the Mediated Habitus from Television to the Mobile Phone. The Communication Review. 2004;7(4):353-362.

9. Delli Carpini MX, Williams BA. Let Us Infotain You: Politics in the New Media Age, In: Bennett WL, Entman R, editors. Mediated Politics: Communication in the Future of Democracy. Cambridge, UK: Cambridge University Press; 2001. pp. 160-181.

10. McChesney RM. Rich Media, Poor Democracies. Urbana, IL, USA: University of Illinois Press; 1999.

11. Murdock GJ, Wasko J, editors. Media in the Age of Marketization. Creskill, NJ, USA: Hampton Press; 2007.

12. Livingstone S, Lunt P. Talk on Television: Audience Participation and Public Debate. London, UK: Routledge; 1994.

13. Bennett WL, Entman R, editors. Mediated Politics: Communication in the Future of Democracy. Cambridge, UK: Cambridge University Press; 2001.
14. Bennett $\mathrm{WL}$, Lawrence RG, Livingstone S. When the Press Fails: Political Power and the News Media from Iraq to Katrina. Chicago, IL, USA: University of Chicago Press; 2007.

15. Cottle S, editor. News, Public Relations and Power. London, UK: Sage; 2003.

16. Gaber I. Government by spin: An analysis of the process. Media, Culture and Society. 2000;22(4): 507-518.

17. Castells M. Communication Power. Oxford, UK: Oxford University Press; 2009.

18. Castells M. Networks of Outrage and Hope: Social Movements in the Internet Age. Cambridge, UK: Polity Press; 2012.

19. Cottle S. Mediatized Conflict. Maidenhead, UK: Open University Press; 2006.

20. Kaplan AM, Haenlein M. Two hearts in threequarter time: How to waltz the social media/viral marketing dance. Business Horizons. 2011;54(3):253263.

21. Van Dijck J. The Culture of Connectivity. A Critical History of Social Media. New York, NY, USA: Oxford University Press; 2013.

22. Uricchio W. Television's next generation: Technology/interface culture/flow. In: Spigel L, Olsson J, editors. Television after TV: Essays on a Medium in Transition. Durham, NC, USA: Duke University Press; 2004. pp. 232-261.

23. Berry DM. The Philosophy of Software. Code and mediation in the digital age. London, UK: Palgrave; 2011.

24. Bucher T. Want to be on the top? Algorithmic power and the threat of invisibility on Facebook. New Media \& Society. 2012;14(7):1164-1180.

25. Beer D. Power through the algorithm? Participatory web cultures and the technological unconsciousness. New Media \& Society. 2009;11(6):985-1002.

26. Ellison NB, Steinfeld C, Lampe C. Connection strategies: Social capital implications of Facebook-enabled communication practices. New Media \& Society. 2011;13(6):873-8892.

27. Gillespie TL. The Politics of Platforms. New Media \& Society. 2010;12(3):347-364.

28. Gillespie TL. The relevance of algorithms. In: Gillespie TL, Bockzkowski P, Foot K, editors. Media Technologies. Cambridge, MA, USA: MIT Press; forthcoming.

29. Uricchio W. The algorithmic turn. Photosynth, augmented reality and the changing implications of the image. Visual Studies. 2011;26(1):25-35.

30. Aalberg T, Stromback J, de Vreese C. The Framing of Politics as Strategy and Game: A Review of Concepts, Operationalizations and Key Findings. Journalism. 2012;13(2):162-178.

31. Rieder B. The refraction chamber: Twitter as sphere and network. First Monday. 2012:17(11). doi: 10.5210/fm.v17i11.4199. Available from: http://firstm onday.org/htbin/cgiwrap/bin/ojs/index.php/fm/issue/vi ew/375 (accessed on 29 July 2013). 
32. Gerlitz C, Helmond A. The Like Economy: Social buttons and the data-intensive web. New Media \& Society. 2013; forthcoming. Available from: http://nms.sagepub.com/content/early/2013/02/03/146144481 2472322.abstract (accessed on 29 July 2013).

33. A Klout score is a number between 1-100 that represents how influential you are in the world of online social networking sites. For more information see: Klout homepage. Available from: http://klout.com/ho me (accessed on 29 July 2013).

34. Lotan G. Data Reveals that Occupying Twitter Trending Topics Is Harder Than It Looks. Social Flow. 12 October 2011. Available from: http://blog.socialflo w.com/post/7120244374/data-reveals-that-occupying-t witter-trending-topics-is-harder-than-it-looks (accessed on 29 July 2013).

35. On 1 May 2012, Mark Zuckerberg announced the implementation of a Facebook tool that promotes organ donation; see, for instance: Blagdon J. The Verge. Available from: http://www.theverge.com/2012/ 5/1/2990831/facebook-organ-donor-timeline. (accessed on 29 July 2013).

36. Jenkins H, Ford S, Green J. Spreadable Media. Creating Value and Meaning in a Networked Culture. New York, NY, USA: New York University Press; 2013.

37. Rasmussen T. Internet-based media, Europe and the political public sphere. Media, Culture \& Society. 2013;35(1):97-104.

38. Haythornthwaite C, Wellman B. Work, friendship and media use for information exchange in a networked organization. Journal of the American Society for Information Science. 1998;49(12):1101-1114.

39. Wellman B. Little Boxes, Glocalization, and Networked Individualism. In: Tanabe $M$, Besselaar $P$, Ishida T, editors. Digital Cities II-Second Kyoto Workshop on Digital Cities. Berlin, Germany: Springer Verlag; 2002. pp. 10-25.

40. Pariser E. The Filter Bubble. What the Internet Is Hiding from You. New York, NY, USA: Viking; 2011.

41. Sunstein CR. Republic.com 2.0. Princeton, PA, USA: Princeton University Press; 2007.

42. Bennett WL, Segerberg A. The Logic of Connective Action, Information. Communication \& Society. 2012;15(5):739-768.

43. McAdam D, McCarthy JD, Zald MN. Introduction: Opportunities, mobilizing structures, and framing processes-Toward a synthetic, comparative perspective on social movements. In: McAdam D, McCarthy JD, Zald MN, editors. Comparative Perspectives on Social Movements: Political Opportunities, Mobilizing Structures, and Cultural Framings. New York, NY, USA: Cambridge University Press; 1996. pp. 1-20.

44. Snow DA, Benford RD. Ideology, frame resonance, and participant mobilization. International Social Movement Research. 1988;1:197-217.

45. Benford RD, Snow DA. Framing processes and social movements: An overview and assessment. Annual Review of Sociology. 2000;26:611-639.

46. Mayer-Schoenberger V, Cukier K. Big Data. A
Revolution that Will Transform How We Live, Work and Think. London, UK: John Murray Publishers; 2013.

47. Andrejevic $M$. The work that affective economics does. Cultural Studies. 2011;25(4-5):604-620.

48. Diakopoulos N, Shamma DA. Characterizing debate performance via aggregated Twitter sentiment. Proceedings of the CHI Conference. Atlanta, GA, USA, 10-15 April 2010. Available from: http://dl.acm.org/cit ation.cfm?id=1753504 (accessed on 29 July 2013).

49. Bollen J, Mao H, Pepe, A. Determining the public mood state by analysis of microblogging posts. Proceedings of the 12th International Conference on the Synthesis and Simulation of Living Systems. Odense, Denmark, October 2010. Available from: http://pti. iu.edu/pubs/determining-public-mood-state-analysismicroblogging-posts. (accessed on 12 March 2013).

50. Pak A, Paroubek P. Twitter as a corpus for sentiment analysis and opinion mining. Proceedings of the 7th Conference on International Language Resources and Evaluation LREC. Valletta, Malta, May 2010. Available from: http://www.bibsonomy.org/bibte x/25656c3bb1adf00c58a85e3204096961c/frederik (accessed on 29 July 2013).

51. Gitelman L, editor. "Raw data" Is an Oxymoron. Cambridge: MIT Press; 2013.

52. Bennett WL, Manheim J. The Big Spin: Strategic communication and the transformation of pluralist democracy. In: Bennett WL, Entman R, editors. Mediated Politics: Communication in the Future of Democracy. Cambridge UK: Cambridge University Press; 2001. pp. 279-298.

53. Rosenthal R, Rosnow R. The Volunteer Subject. New York, NY, USA: John Wiley \& Sons Inc.; 1975.

54. In March 2013, the American-based company Nielsen Inc. announced a partnership with Twitter to measure audience attention. According to a study funded by both partners, there are strong correlations between Twitter and TV ratings. For premiere episodes, an $8.5 \%$ increase in Twitter volume is associated with a $1 \%$ increase in TV program ratings for 18-34 year olds. Additionally, a $14.0 \%$ increase in Twitter volume is associated with a $1 \%$ increase in TV program ratings for 35-49 year olds, reflecting a stronger relationship between Twitter and TV for younger audiences. See: Nielsen webpage. 3 March 2013. Available from: http://www.nielsen.com/us/en/ press-room/2013/new-study-confirms-correlation-bet ween-twitter-and-tv-ratings.html (accessed on 29 July 2013).

55. Larsson AO, Moe H. Studying political microblogging: Twitter users in the 2010 Swedish election campaign. New Media \& Society. 2012:14(5):729-747.

56. Burgess J, Bruns A. (Not) the Twitter election. The dynamics of the \#ausvotes conversation in relation to the Australian media ecology. Journalism Practice. 2012;6(3):384-402.

57. Chun WHK. Programmed Visions. Software and Memory. Cambridge, MA, USA: MIT Press; 2011.

58. Amoore L. Data Derivatives on the Emergence 
of a Security Risk Calculus for Our Times. Theory, Culture \& Society. 2011;28(6):24-43.

59. Latour B. Reassembling the Social. An Introduction to Actor-Network Theory. New York, NY, USA: Oxford University Press; 2005.

60. Morozov E. The Net Delusion. How Not to Liberate the World. New York, NY, USA: Penguin; 2011.

61. Poell T, Darmoni K. Twitter as a multilingual space: The articulation of the Tunisian revolution through \#sidibouzid. The European Journal of Media Studies. 2012;1(1). Available from: http://www.necs us-ejms.org/twitter-as-a-multilingual-space-the-articu lation-of-the-tunisian-revolution-through-sidibouzid-by -thomas-poell-and-kaouthar-darmoni/ (accessed on 29 July 2013). 